\title{
Surface treatment of incrementally produced components in FFF (Fused Filament Fabrication) technology
}

\author{
Maciej Mrówka ${ }^{1), *)}$, Tomasz Machoczek ${ }^{1)}$, Małgorzata Szymiczek¹), Przemysław Gągol ${ }^{11}$, \\ Sławomir Duda ${ }^{1)}$, Łukasz Marcoll2)
}

DOI: dx.doi.org/10.14314/polimery.2020.1.7

\begin{abstract}
The aim of the conducted research was to examine the possibility of using chemical and physical methods of surface treatment of elements printed on a 3D printer. Elements were printed from polylactide (PLA) and acrylonitrile-butadiene-styrene (ABS) - materials most commonly used in fused filament fabrication (FFF) technology. Roughness measurements were made to assess the quality of individual methods. The best surface smoothness results were obtained during abrasive paper processing and after applying epoxy resin. The intended effect was also obtained after processing samples from PLA in chloroform fumes, and ABS samples in acetone vapors.
\end{abstract}

Keywords: FFF (Fused Filament Fabrication), polylactide (PLA), acrylonitrile-butadiene-styrene (ABS), surface treatment, surface roughness.

\section{Obróbka powierzchniowa elementów wytwarzanych przyrostowo w technologii FFF (Fused Filament Fabrication)}

Streszczenie: Zbadano możliwości wykorzystania chemicznych i fizycznych metod obróbki powierzchniowej elementów wydrukowanych za pomocą drukarki 3D. Elementy wytworzono z polilaktydu (PLA) i kopolimeru akrylonitrylo-butadieno-styrenowego (ABS) - materiałów najpowszechniej stosowanych w technologii Fused Filament Fabrication (FFF). Jakość wykonania przy użyciu poszczególnych metod oceniano na podstawie chropowatości powierzchni wytworzonych elementów. Najlepszą gładkość powierzchni uzyskano w wyniku obróbki wydrukowanych elementów papierami ściernymi i nałożeniu żywicy epoksydowej. Zamierzony efekt uzyskano też w wyniku obróbki próbek z PLA w oparach chloroformu, a próbek z ABS w oparach acetonu.

Słowa kluczowe: FFF (Fused Filament Fabrication), polilaktyd (PLA), kopolimer akrylonitrylo-butadieno-styrenowy (ABS), obróbka powierzchniowa, chropowatość powierzchni.

The FFF (Fused Filament Fabrication) technology is based on the material layering on the work table and then on the existing part of the model. The material is a plasticized polymer extruded through a nozzle. The material is supplied to the nozzle in the form of a wire called filament. The filament is wound on a spool and is pushed into the nozzle by means of a feeding mechanism called an extruder. The plasticized material is placed in paths which, while cooling down, connect with the lower path. Pathways form layers and so layer by layer a finished model is created [1-5]. The movements of the extruder and work platform and the temperatures of the table and nozzle are controlled by integrated circuits in the printer [6].

\footnotetext{
1) Silesian University of Technology, Institute of Theoretical and Applied Mechanics, Faculty of Mechanical Engineering, Konarskiego 18 A, 44-100 Gliwice, Poland.

2) Marcoll Sp. z o.o., Kotuchy 20, 41-946 Piekary Śląskie, Poland.

*) Author for correspondence; e-mail: maciej.mrowka@polsl.pl
}

The advantages of FFF technology are the speed of creation of ready elements, high availability of materials with different mechanical and physicochemical properties [7]. Printout processing is also simple and can be carried out in many ways. Disadvantages of this method are the visible layers, which in some applications can be a problem. Another disadvantage is the partial filling of the printout, which significantly reduces the strength $[7,8]$. Of course you can make a solid print, but this will have a significant impact on the time of its creation. The use of this technology allows you to make prototypes in almost every field of production and creation. In FFF technology, the material is laid by the nozzle in layers, which leads to the formation of a rough surface perpendicular to the applied layers [1-5]. Depending on the adopted print resolution, it will vary. The lower the resolution, the rougher the surface and the distance between the ridges of roughness will be greater. Unfortunately, even the highest resolution will not eliminate this problem, because the surface roughness will be large enough to damage the sand casting form. Therefore, 
the essence of the project will be to select the optimal method of surface treatment of the models. An additional goal is also to maintain the highest possible dimensional accuracy of the model [7-9]. The FFF technology is limited to the use of thermoplastics, because the material extruded through the nozzle must be plastic in order to be able to shape it directly on the workpiece into a path. Initially, the commonly used materials were PLA (polylactide) and ABS (acrylonitrile-butadiene-styrene). Over time, new materials such as ASA (acrylonitrile), polyamides, PVA [poly(vinyl alcohol)], HIPS (high impact polystyrene), PET [poly(ethylene terephthalate)], PC (polycarbonate), HDPE (high density polyethylene), PP (polypropylene), TPU (thermoplastic polyurethane elastomer) were introduced [7]. In FFF technology the most widely used materials are PLA and ABS [1-8]. The first one is a polymer with a density of about $1.24 \mathrm{~g} / \mathrm{cm}^{3}$. It is obtained from renewable, biodegradable natural resources. It is used in medicine for the production of restorable surgical threads or dental implants. It is also used in 3D printing [10]. During the extrusion process PLA is characterized by small shrinkage, which is beneficial for the printing process. Printing temperatures range from $190{ }^{\circ} \mathrm{C}$ to $230{ }^{\circ} \mathrm{C}$ depending on the printer in use, the filament manufacturer or the extruder construction [11]. PLA surface treatment is not the simplest, because it is a material whose softening temperature is $60{ }^{\circ} \mathrm{C}$ and easy to achieve by rubbing the surface made of this material with sandpaper. In this case, the abrasive material starts to form lumps, seal the abrasive paper, which prevents further processing with the same piece of abrasive material [12, 13]. ABS is a thermoplastic copolymer obtained by polymerization of butadiene with acrylonitrile and styrene. ABS has good mechanical properties, is resistant to ultraviolet light and has a high electrical resistance. Additionally, it is resistant to scratches and its softening temperature without load is above $90^{\circ} \mathrm{C}$ [14]. It is used in the automotive industry and industrial electronics products. It is used as an engineering material in $3 \mathrm{D}$ printing. Its use is not only for prototyping, but it can be used to produce finished products with full functionality. Unfortunately, during extrusion and cooling ABS has a shrinkage of $0.4-0.7 \%$, which causes problems in the printing process [14-16]. Depending on the manufacturer and admixtures, ABS is printed with a nozzle at temperatures from $220{ }^{\circ} \mathrm{C}$ to $260{ }^{\circ} \mathrm{C}$ [14-17]. The material is available in different colors and with different modifiers. The surface treatment of the material can be carried out in acetone vapor because this solvent reacts with ABS by vulcanizing it surface. Abrasive treatment is also facilitated by a higher softening temperature $[14,16,17]$.

\section{EXPERIMENTAL PART}

\section{Materials}

Cubes printed of PLA and ABS were used for the tests (both filaments were purchased from the company F3d
Filament, Poland). Sanding paper (mesh diameter) was purchased in the company Norton. Hairspray was purchased in the company Wella. Epoxy resin (Epidian 5) was purchased in the company Ciech S.A. Organic solvents: methyl alcohol (pure 99\%), ethyl alcohol (pure 70\%), isopropanol alcohol (pure 99\%), DMSO (dimethyl sulfoxide, pure $99 \%$ ), toluene (pure 99\%), THF (tetrahydrofurane, pure $99 \%$ ), acetone (pure 99\%), chloroform (pure 99\%) were purchased from ChemPur (Poland).

\section{Preparation of specimens for testing}

The first step was to perform elimination tests in order to reduce the number of specimens. The first step was to make 12 cubes of $50 \times 50 \times 50 \mathrm{~mm}, 6$ of each material (PLA, $\mathrm{ABS}$ ), in 6 different print resolutions: $0.06 \mathrm{~mm}$; $0.1 \mathrm{~mm} ; 0.15 \mathrm{~mm} ; 0.2 \mathrm{~mm} ; 0.3 \mathrm{~mm} ; 0.4 \mathrm{~mm}$. Each specimen had to be tested for roughness with the profile gauge and that one of each material should be chosen which roughness was advantageous.

During the elimination tests, fixed values were assumed for the printing of specimens. The printer that was used to print all specimens was Urbicum MX. Fixed values of the printed models are:

- software used: Cura 3.5;

- printing speed: $100 \mathrm{~mm} / \mathrm{s}$;

- filling: $10 \%$;

- number of contours (thickness of external walls): 3;

- printing of exterior walls from the inside to the outside;

- nozzle diameter: $0.4 \mathrm{~mm}$;

- nozzle temperature: $200^{\circ} \mathrm{C}$ for PLA, $240{ }^{\circ} \mathrm{C}$ for ABS;

- table temperature: $50{ }^{\circ} \mathrm{C}$ for PLA, $90{ }^{\circ} \mathrm{C}$ for ABS + chamber;

- cooling $70 \%$ for PLA, $0 \%$ for ABS.

After selecting specific sample resolutions, 16 samples of each material to be machined were printed. They were printed on a 3DGence One printer with the following parameters:

- software used: Simplify3D;

- printing speed: $50 \mathrm{~mm} / \mathrm{s}$;

- filling: $10 \%$;

- number of contours (thickness of external walls): 3;

- printing of exterior walls from the inside to the outside;

- nozzle diameter: $0.4 \mathrm{~mm}$;

- nozzle temperature: $210{ }^{\circ} \mathrm{C}$ for PLA, $245^{\circ} \mathrm{C}$ for ABS;

- table temperature: $50{ }^{\circ} \mathrm{C}$ for PLA, $90{ }^{\circ} \mathrm{C}$ for ABS + chamber;

- cooling 70\% for PLA, $0 \%$ for ABS.

The introduction of elimination tests allowed reducing the number of tested specimens from 192 (in materials $\times 6$ resolution $\times 16$ types of treatment), which would require treatment to 44 , of which only 32 ( 2 materials $\times 1$ resolution $\times 16$ treatments) required treatment. The remaining materials required only roughness measurement for elimination purposes. The use of two independent 
printing devices was associated with the use of two different types of materials, which in turn are characterized by different printing parameters. As a result, their settings were selected independently, so that in the end, get the best result.

\section{Elimination tests}

The elimination tests began with the printing of sample $20 \mathrm{~mm} \times 20 \mathrm{~mm} \times 20 \mathrm{~mm}$ cubes in FFF technology from PLA and ABS materials. The resolutions in which it was printed were as follows: $0.06 \mathrm{~mm}, 0.1 \mathrm{~mm}, 0.15 \mathrm{~mm}$, $0.2 \mathrm{~mm}, 0.3 \mathrm{~mm}$ and $0.4 \mathrm{~mm}$. These are the most commonly used printing resolutions using a nozzle with a diameter of $0.4 \mathrm{~mm}$. A total of 12 test cubes measuring $50 \mathrm{~mm} \times 50 \mathrm{~mm} \times 50 \mathrm{~mm}$ were made. Each of them was measured with a profile gauge and the results are shown in Table 1 and Table 2. The most important parameters were $R a$ (mean arithmetic deviation from the mean line) and $S m$ (mean roughness interval). The measurement focused on the height of roughness and the distance between the intervals of roughness. In order to have a closer look at the surface quality, macro scale photographs were also taken. The photographs also allowed visual evaluation in order to select the resolution used in the further tests.

\section{Selection of resolution for further tests}

Based on the results of elimination tests, we are able to determine that the smoothness of samples surface increases with increasing resolution. In order to make it easier to smooth out the samples later, it would be best to print samples in $0.06 \mathrm{~mm}$ or $0.1 \mathrm{~mm}$ resolution, because the smoothness of these samples is the highest. There is no significant difference in surface quality between $0.06 \mathrm{~mm}$ and $0.1 \mathrm{~mm}$. The disadvantage of this choice is that the printing time of one cube is much longer. Significant roughness of the surface and lines of the layer are visible only when applying a layer height from $0.2 \mathrm{~mm}$. For comparison, the printing time of a single cube is shown in Table 3. The printing speed used for calculations by Simplify3D is $100 \mathrm{~mm} / \mathrm{sec}$. Due to the two factors described above, a compromise was reached, and a resolution of $0.2 \mathrm{~mm}$ was selected for further printing. An additional argument in favor of $0.2 \mathrm{~mm}$ resolution is the fact that this is the most commonly used layer height among FFF technology users.

\section{Machining}

When machining, be aware that polymers soften at a much lower temperature than metal materials, which are often ground. The softening temperature of the most commonly used materials in printing by FFF technology ranges from $55^{\circ} \mathrm{C}$ to $125^{\circ} \mathrm{C}$. Due to the low softening temperatures, abrasive processing is difficult and requires an additional heat-absorbing agent. Two types of abrasive were used in the tests. The first was the use of abrasive papers with increasing grain-size without the use of coolant. The papers with the following grain-size distribution were used in turn: 38, 60, 80, 120, 180, 220, 280, 320, 400, 500, 600, 800, 1000, 1500, 2000 and 2500. During processing, circular movements were made with paper over the specimen in order to evenly ground the surface. It was also necessary to take frequent breaks in order not to overheat the material and not to stick the abrasive paper with it. This applies in particular to PLA specimens that soften at $55{ }^{\circ} \mathrm{C}$. The second type of abrasive treatment was the use of waterproof abrasive papers with increasing grain size-distribution. In this case a water-based coolant was used. Before using paper with a specific grain size, it was immersed in water. The same was done with the specimen to remove dust after treatment with the paper of the previous grain size. The following grain-size distributions of paper were used: $60,80,120$, 180, 220, 260, 320, 360, 400, 500, 600, 800, 1000, 1500, 2000 and 2500 . The abrasive machining was carried out in two stages. In the first stage, samples were sanded with 38,60 , $80,120,180,220,280,320,400,500$ graded abrasive paper, dry in a direction parallel to the edge of the sample, and the sample was rotated by 90 degrees. Manual processing of samples was carried out using a trowel grinding. The processing time was 1 minute. In the second stage, wet processing was carried out (paper and sample was moistened every 15 seconds to cool the material and remove any dust formed from the sample and sandpaper), circular motion, 600, 800, 1000, 1500, 2000 and 2500 gradation paper. The paper used for grinding was wet all the time during contact with the sample. An additional method of mechanical treatment was smoothing the sample with wet abrasive paper as described above and to applying a layer of lacquer after degreasing the surface. The lacquer layer allows changing the color of the printout and give it a greater gloss. It also serves as a protective layer of the proper material. It protects against scratches and impact of chemical agents.

\section{Additive treatment}

In contrast to mechanical treatment, additive treatment will consist in removing roughness not by cutting, but by applying an additional layer to cover roughness. The first method consisted in coating the lateral surface of the printout only with an agent used as last one in the regular painting or varnishing process. The surfaces were degreased with extraction gasoline before the application of varnishes in order to improve adhesion of the coating and to avoid the formation of air bubbles. No other pre-treatment has been carried out. The second one consisted in mechanical cleaning of the surface and degreasing it with extraction gasoline. Next, a polymer finishing putty was applied on subsequent specimens and then sanded off; epoxy resin; primer layer and then two 
$\mathrm{T}$ a b l e 1. Results of measurement of roughness of PLA elimination samples

\begin{tabular}{c|c|c|c|c|c|c|c|c|c|c|c|c}
\hline \multicolumn{10}{c}{$\begin{array}{c}\text { Payer height } \\
\text { mm }\end{array}$} & \multicolumn{9}{|c|}{$R a, \mu \mathrm{m}$} & \multicolumn{3}{c}{ Sm, $\mu \mathrm{m}$} \\
\hline 0.06 & 7.6 & 7.4 & 8 & 7.6 & 7.6 & 7.6 & 108 & 106 & 107 & 102 & 105 & 105.6 \\
0.1 & 8.4 & 8.6 & 7.4 & 8.2 & 7.6 & 8.0 & 128 & 132 & 115 & 124 & 113 & 122.4 \\
0.15 & 11.8 & 11.8 & 11.8 & 12 & 10.6 & 11.6 & 165 & 163 & 159 & 172 & 155 & 162.8 \\
0.2 & 16.2 & 16 & 16 & 16.2 & 16.4 & 16.2 & 216 & 206 & 213 & 216 & 213 & 212.8 \\
0.3 & 24.6 & 24.6 & 26 & 24 & 24.6 & 24.8 & 304 & 304 & 312 & 312 & 304 & 307.2 \\
0.4 & 34 & 33.4 & 32.2 & 33.8 & 33.8 & 33.4 & 421 & 409 & 405 & 405 & 404 & 408.8 \\
\hline
\end{tabular}

$\mathrm{T}$ a b 1 e 2. Results of measurement of roughness of ABS elimination samples

\begin{tabular}{|c|c|c|c|c|c|c|c|c|c|c|c|c|}
\hline \multicolumn{13}{|c|}{ ABS } \\
\hline $\begin{array}{l}\text { Layer height } \\
\mathrm{mm}\end{array}$ & \multicolumn{6}{|c|}{$R a, \mu \mathrm{m}$} & \multicolumn{6}{|c|}{$S m, \mu \mathrm{m}$} \\
\hline 0.06 & 11.9 & 11.9 & 11.9 & 11.6 & 11.6 & 11.8 & 193 & 193 & 193 & 157 & 147 & 176.6 \\
\hline 0.1 & 19.3 & 19.7 & 19 & 18.9 & 20.3 & 19.4 & 155 & 162 & 191 & 185 & 363 & 211.2 \\
\hline 0.15 & 27.3 & 27.4 & 27.3 & 27.4 & 27.3 & 27.3 & 175 & 180 & 180 & 177 & 179 & 178.2 \\
\hline 0.2 & 30.9 & 30.9 & 31.3 & 31.3 & 31.3 & 31.1 & 249 & 249 & 249 & 249 & 248 & 248.8 \\
\hline 0.3 & 33.8 & 33.8 & 33.9 & 34.7 & 34.8 & 34.2 & 343 & 341 & 340 & 339 & 339 & 340.4 \\
\hline 0.4 & 30 & 29.7 & 29.7 & 29.1 & 29.5 & 29.6 & 517 & 542 & 541 & 538 & 537 & 535 \\
\hline
\end{tabular}

layers of varnish all at two-hour intervals. All treatments were carried out under constant conditions: temperature $22{ }^{\circ} \mathrm{C}$ and humidity 55\%.

\section{Chemical treatment}

Chemical treatment consisted in exposing the printout to solvents. First in direct contact to check the reactivity of the solvent with a specific polymer, and then immersing the sample in the vapor of subsequent reagents. Prior to use, the reagents were conditioned at $21{ }^{\circ} \mathrm{C}$ for $24 \mathrm{~h}$. PLA samples were exposed to ethanol, methyl alcohol, isopropanol, DMSO, toluene, chloroform and THF. In addition, PolySmooth ${ }^{\mathrm{TM}}$ filament from Polymaker in isopropanol vapor was tested (the manufacturer recommends such a way of smoothing out the prints from this material). The ABS samples were exposed to all reagents like the previous ones and were additionally used for acetone testing.

\section{RESULTS AND DISCUSSION}

\section{Selection of the resolution to tests}

On the basis of the results of elimination tests, it was determined that the smoothness increases with increasing resolution (lowering the layer height) (Tables 1, 2). In order to facilitate subsequent smoothing of samples, it would be best to print samples in $0.06 \mathrm{~mm}$ or $0.1 \mathrm{~mm}$ resolution, because the smoothness of these samples is the highest. There is no significant difference in surface quality between $0.06 \mathrm{~mm}$ and $0.1 \mathrm{~mm}$ layer printing.
This can be seen in the pictures and in the Figs. 1 and 2 . The disadvantage of this choice is that the printing time of one cube is much longer. Significant roughness of the surface and lines of the layer are visible only when applying a layer height from $0.2 \mathrm{~mm}$. For comparison, the printing time of a single cube is shown in Table 3. The printing speed used by Simplify3D is $100 \mathrm{~mm} / \mathrm{s}$. Due to the two factors described above, a compromise was reached and a resolution of $0.2 \mathrm{~mm}$ was selected for further printing. An additional argument in favor of $0.2 \mathrm{~mm}$ resolution is the fact that it is the most commonly used layer height among FFF users.

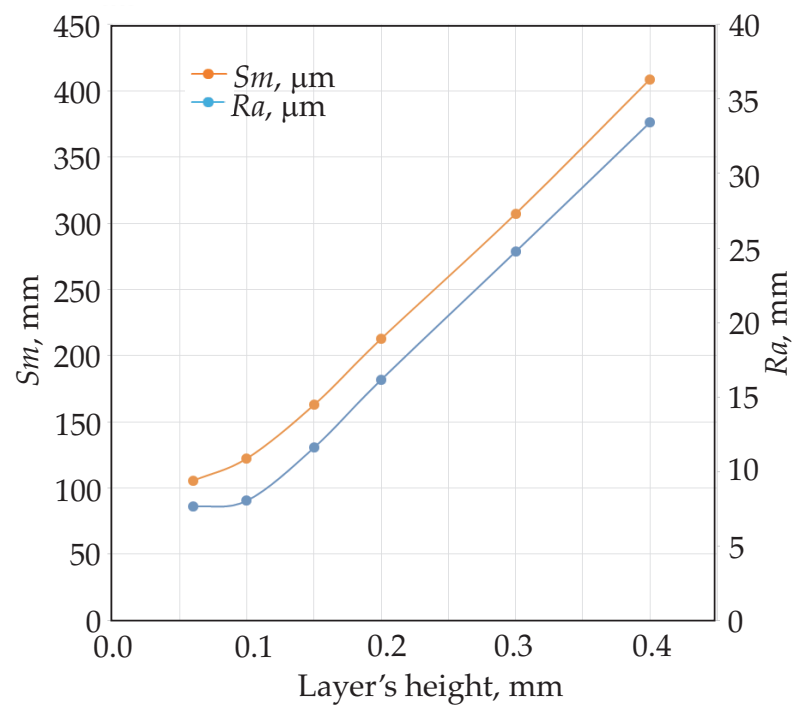

Fig. 1. Dependence of surface roughness coefficients on the printed layer height for PLA 


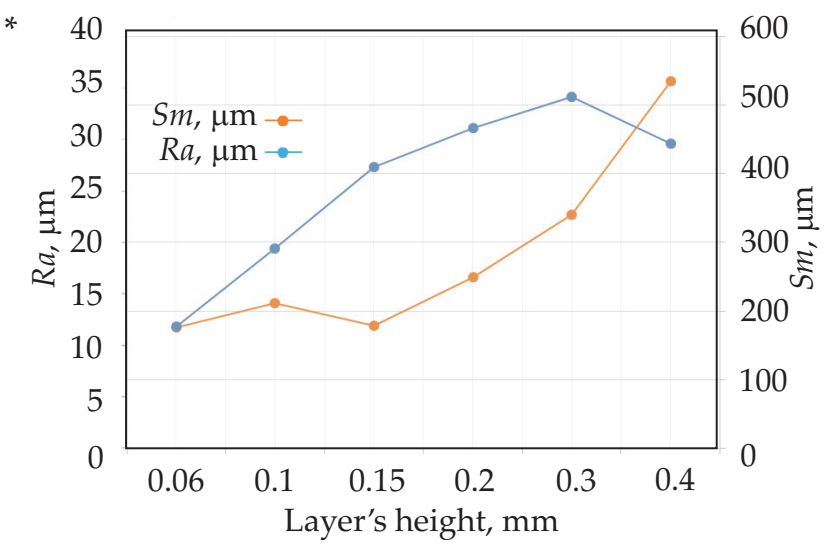

Fig. 2. Dependence of surface roughness coefficients on the printed layer height for ABS

$\mathrm{T}$ a b l e 3. Dependence of printing time of $50 \mathrm{~mm} \times 50 \mathrm{~mm} \times$ $50 \mathrm{~mm}$ cube depending on the height of the layer

\begin{tabular}{c|c}
\hline Layer height, $\mathrm{mm}$ & Printing time \\
\hline 0.4 & $53 \mathrm{~min}$ \\
0.3 & $1 \mathrm{~h} 7 \mathrm{~min}$ \\
0.2 & $1 \mathrm{~h} 36 \mathrm{~min}$ \\
0.15 & $2 \mathrm{~h} 4 \mathrm{~min}$ \\
0.1 & $3 \mathrm{~h} 1 \mathrm{~min}$ \\
0.06 & $4 \mathrm{~h} 55 \mathrm{~min}$ \\
\hline
\end{tabular}

\section{Evaluation of samples made of PLA}

A sample with a layer height of $0.2 \mathrm{~mm}$ was used as the output resolution. The Figs. 3-7 clearly show the horizontal ribbing resulting from the process technology. Below, the drawings from /to show the surfaces of the processed printouts. The photos were taken on a macro scale to show possible surface irregularities.
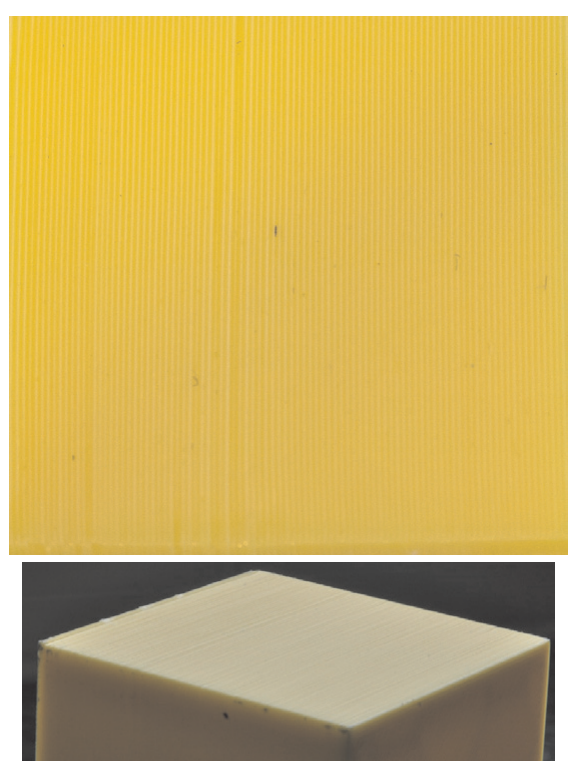

Fig. 3. Removal of the surface of PLA printout at $6 \times$ magnification - the layer height is $0.2 \mathrm{~mm}$

There are samples which do not show any improvement in surface quality in the first visual evaluation. Surfaces are treated with ethyl alcohol, methyl alcohol, isopropanol, DMSO. After DMSO treatment a white sludge was left on the surface. These methods will certainly not find application in smoothing the surface for the purpose of creating molds.

Additive treatments with the use of lacquer, lacquer primer and lacquer as well as nail polish did not result in visual setting either. What is more, they showed the layers on the side wall of the printout. Painting with nail polish - apart from the fact that it did not cover the visible layers - additionally left an irregular pattern on the surface. Quite good results were achieved after treating PLA with toluene and tetrahydrofuran. The layers became blurred, while the roughness remained visible and noticeable. A similar result was achieved during PLA treatment with PolySmooth ${ }^{\mathrm{TM}}$ isopropanol. The picture shows the layers, but they are smoothed out. It is possible that prolonged exposure to the agent would contribute to an even greater improvement in surface quality. A positive result was also obtained in the case of covering the surface of the print with a finishing putty. The resulting layer was easy to process. Scratches visible on the drawing are not noticeable when moving the finger over the surface. The characteristic buzzing when moving the nail on the surface cannot be listen too. The best results were obtained when working with abrasive papers as well as after painting the previously polished surface. The use of epoxy resin covered all irregularities and significantly smoothed out the roughness. The most uniform result was obtained after immersion of the sample in chloroform vapor. The surface is noticeably smooth, without any unevenness. The base color of the sample also remained. Little can be seen in the drawings because the surface was so smooth that the camera did not find a point

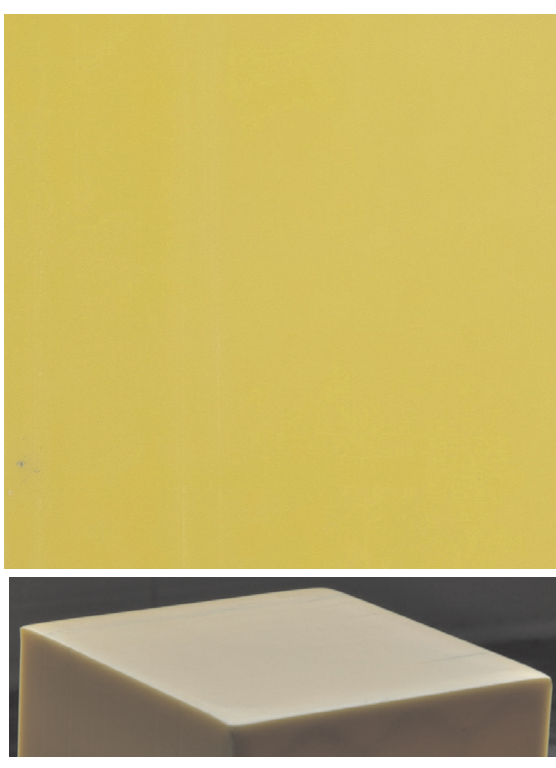

Fig. 4. Mechanical machining of PLA plastic sample by dry grinding

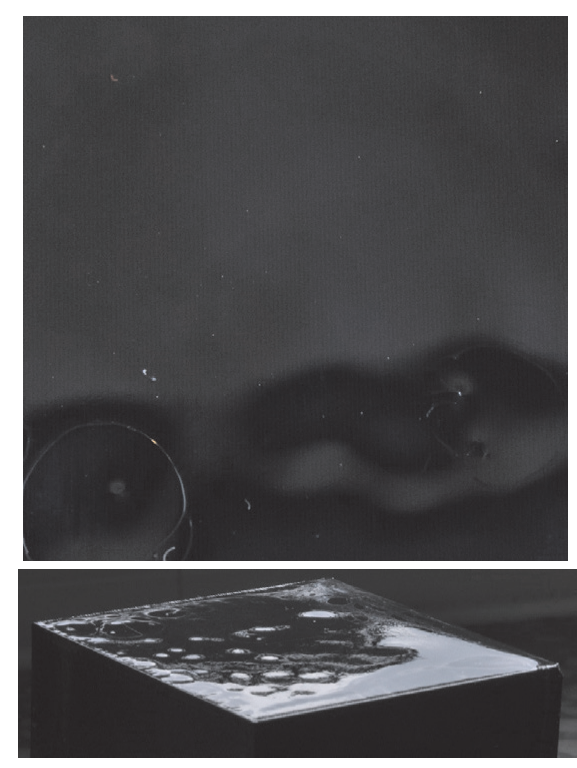

Fig. 5. Additive treatment of PLA sample by applying an epoxy resin layer 

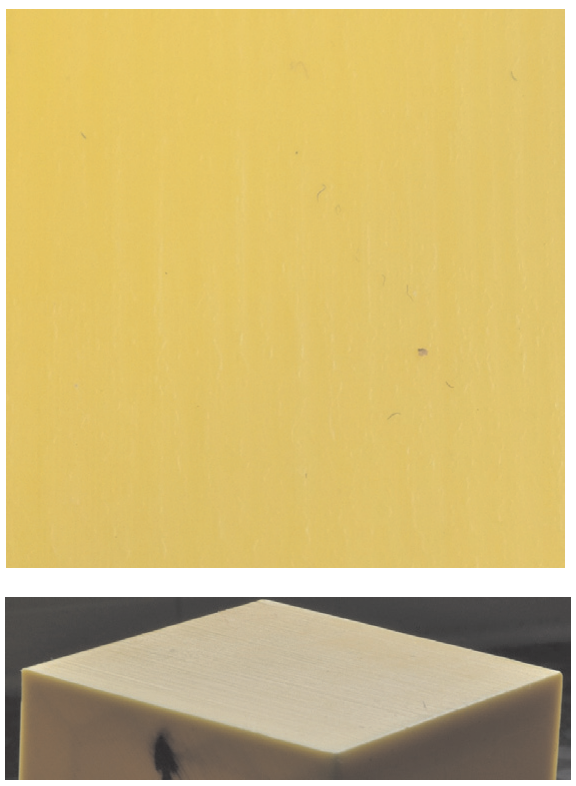

Fig. 6. Chemical treatment of PLA sample using toluene

at which it could catch the focus. The structure shown in the figure is smooth to the touch. The color changes result from the different orientation of the varnish on the surface of the polished printout. During abrasive treatment, a satisfactory surface quality was obtained after the use of the abrasive paper with the grain-size 500 for dry processing, while for wet processing a satisfactory result was achieved after the use of 320 paper. In addition, water facilitated dust extraction after treatment with the previous paper, which also improved the surface quality. The disadvantage of sanding paper was the uneven removal of the material. After grinding, it was noticed that the corners of the cube are more ground than the center of the cube walls.

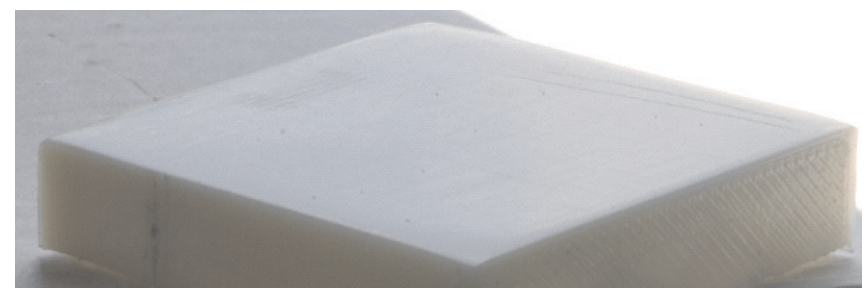

Fig. 8. Mechanical machining of ABS plastic sample using dry sandpaper

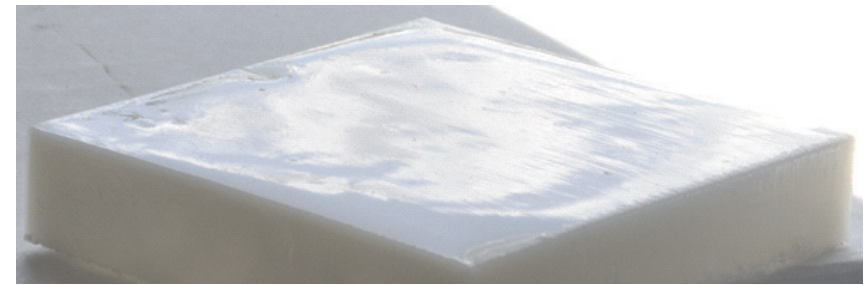

Fig. 10. Additive treatment of ABS plastic sample using an epoxy resin

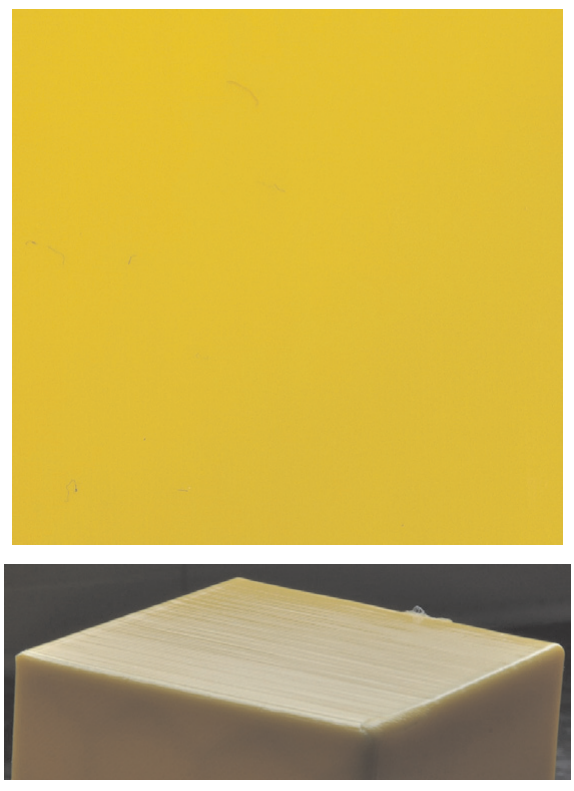

Fig. 7. Chemical treatment of PLA sample using chloroform

\section{Evaluation of samples made of ABS}

In the same way as for PLA samples, the layer height was assumed to be equal to $0.2 \mathrm{~mm}$ for ABS cubes. When taking pictures of the printing surface, it turned out that the camera is not able to record the roughness of the surface, because the samples were made of white filament, which reflects a lot of light. The photographs of the macro surface after treatment are shown in the Figs. 8-11.

As with PLA, there are samples of ABS which, despite the treatment, do not show any improvement in surface quality. Chemical treatment of ABS with ethanol, methyl alcohol, isopropanol and toluene did not produce any results. Minimal effects are visible after direct contact of the

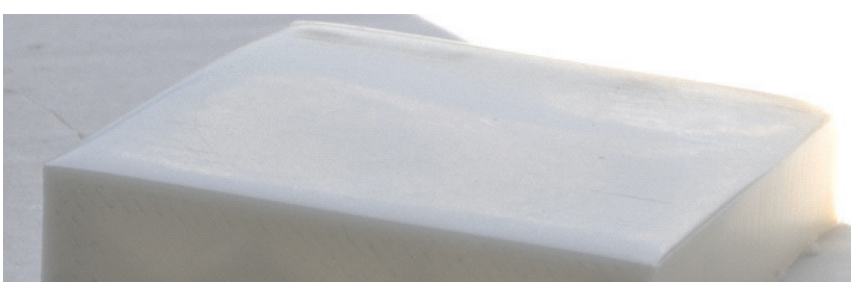

Fig. 9. Mechanical machining of ABS plastic sample using wet abrasive paper

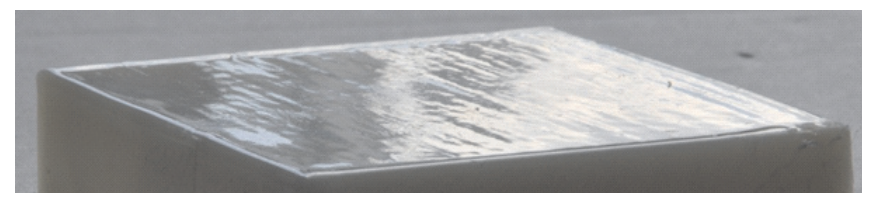

Fig. 11. Chemical treatment of ABS plastic samples using acetone 
$\mathrm{T}$ a b 1 e 4. Summary of roughness measurement results for PLA samples

\begin{tabular}{|c|c|c|c|c|c|c|c|c|c|c|c|c|}
\hline \multirow{3}{*}{ Treatment type } & \multicolumn{12}{|c|}{ PLA } \\
\hline & \multicolumn{4}{|c|}{$\mathrm{Sm}, \mathrm{mm}$} & \multicolumn{4}{|c|}{$R a, \mu \mathrm{m}$} & \multicolumn{4}{|c|}{$R z, \mu \mathrm{m}$} \\
\hline & meas. 1 & meas. 2 & meas. 3 & aver. & meas. 1 & meas. 2 & meas. 3 & aver. & meas. 1 & meas. 2 & meas. 3 & aver. \\
\hline $\begin{array}{l}\text { Abrasive } \\
\text { paper by wet } \\
\text { machining }\end{array}$ & 0.772 & 1.04 & 0.964 & 0.925 & 0.264 & 0.26 & 0.256 & 0.260 & 1.74 & 1.7 & 1.72 & 1.72 \\
\hline $\begin{array}{l}\text { Abrasive } \\
\text { paper by dry } \\
\text { machining }\end{array}$ & 0.33 & 0.229 & 0.252 & 0.270 & 0.269 & 0.278 & 0.265 & 0.271 & 1.67 & 1.65 & 1.55 & 1.62 \\
\hline $\begin{array}{c}\text { Abrasive } \\
\text { paper by wet } \\
\text { machining + } \\
\text { lacquer }\end{array}$ & 1.19 & 0.107 & 2.32 & 1.206 & 0.107 & 0.119 & 0.114 & 0.113 & 0.627 & 0.629 & 0.644 & 0.633 \\
\hline Lacquer & 0.689 & 0.843 & 0.824 & 0.785 & 1.5 & 1.52 & 1.51 & 1.510 & 5.51 & 5.52 & 5.53 & 5.52 \\
\hline$\underset{\text { lacquer }}{\text { Lacquer primer }}+$ & 0.502 & 0.502 & 0.502 & 0.502 & 3.22 & 3.19 & 3.16 & 3.190 & 10.7 & 10.6 & 10.5 & 10.60 \\
\hline Filler & 0.271 & 0.265 & 0.284 & 0.273 & 2.2 & 2.3 & 2.32 & 2.273 & 10.3 & 10.8 & 10.7 & 10.60 \\
\hline Epoxy resin & 0.03 & 0.0344 & 0.036 & 0.033 & 0.204 & 0.202 & 0.204 & 0.203 & 1.11 & 1.07 & 1.13 & 1.10 \\
\hline Nail polish & 0.658 & 0.659 & 0.659 & 0.659 & 2.22 & 2.22 & 2.24 & 2.227 & 7.5 & 7.45 & 7.59 & 7.51 \\
\hline Methyl alcohol & 0.28 & 0.287 & 0.286 & 0.284 & 7.75 & 7.75 & 7.77 & 7.757 & 30.6 & 30.5 & 30.6 & 30.57 \\
\hline Ethanol & 0.256 & 0.261 & 0.26 & 0.259 & 7.87 & 7.88 & 7.91 & 7.887 & 31 & 30.8 & 31.1 & 30.97 \\
\hline Isopropanol & 0.323 & 0.34 & 0.34 & 0.334 & 8.03 & 8.07 & 8.06 & 8.053 & 31.3 & 31.3 & 31.2 & 31.27 \\
\hline DMSO & 0.509 & 0.463 & 0.492 & 0.488 & 3.54 & 3.61 & 3.54 & 3.563 & 15.4 & 15.7 & 15.5 & 15.53 \\
\hline Toluene & 0.65 & 0.755 & 0.814 & 0.740 & 1.24 & 1.34 & 1.35 & 1.310 & 6.13 & 6.46 & 6.34 & 6.31 \\
\hline Chloroform & 2.94 & 2.35 & 2.35 & 2.547 & 1.05 & 1.05 & 1.03 & 1.043 & 3.92 & 3.9 & 3.78 & 3.87 \\
\hline THF & 0.651 & 0.77 & 0.72 & 0.714 & 0.961 & 0.93 & 0.891 & 0.927 & 4.8 & 4.72 & 4.41 & 4.64 \\
\hline $\begin{array}{c}\text { Filament } \\
\text { PolySmooth + } \\
\text { Isopropanol }\end{array}$ & 0.47 & 0.489 & 0.456 & 0.472 & 2.93 & 2.93 & 2.93 & 2.930 & 9.59 & 9.59 & 9.65 & 9.61 \\
\hline
\end{tabular}

T a b 1 e 5. Summary of roughness measurement results for ABS sample

\begin{tabular}{|c|c|c|c|c|c|c|c|c|c|c|c|c|}
\hline \multirow{3}{*}{ Treatment type } & \multicolumn{12}{|c|}{ ABS } \\
\hline & \multicolumn{4}{|c|}{$\mathrm{Sm}, \mathrm{mm}$} & \multicolumn{4}{|c|}{$R a, \mu \mathrm{m}$} & \multicolumn{4}{|c|}{$R z, \mu \mathrm{m}$} \\
\hline & meas. 1 & meas. 2 & meas. 3 & aver. & meas. 1 & meas. 2 & meas. 3 & aver. & meas. 1 & meas. 2 & meas. 3 & aver. \\
\hline $\begin{array}{l}\text { Abrasive } \\
\text { paper by wet } \\
\text { machining }\end{array}$ & 0.0328 & 0.0329 & 0.0319 & 0.033 & 0.193 & 0.195 & 0.184 & 0.191 & 0.87 & 0.86 & 0.81 & 0.85 \\
\hline $\begin{array}{l}\text { Abrasive } \\
\text { paper by dry } \\
\text { machining }\end{array}$ & 1.51 & 1.5 & 1.1 & 1.370 & 0.268 & 0.279 & 0.287 & 0.278 & 1.57 & 1.58 & 1.65 & 1.60 \\
\hline $\begin{array}{c}\text { Abrasive } \\
\text { paper by wet } \\
\text { machining + } \\
\text { lacquer }\end{array}$ & 0.326 & 0.22 & 0.187 & 0.244 & 0.178 & 0.222 & 0.279 & 0.226 & 1 & 1.16 & 1.5 & 1.22 \\
\hline Lacquer & 0.358 & 0.347 & 0.358 & 0.354 & 2.98 & 2.98 & 2.99 & 2.983 & 10.4 & 10.1 & 10.2 & 10.23 \\
\hline $\begin{array}{c}\text { Lacquer primer }+ \\
\text { lacquer }\end{array}$ & 0.42 & 0.405 & 0.391 & 0.405 & 3.95 & 3.93 & 3.93 & 3.937 & 13 & 13.1 & 13 & 13.03 \\
\hline Filler & 0.503 & 0.565 & 0.628 & 0.565 & 3.2 & 2.75 & 2.79 & 2.913 & 13.6 & 12.2 & 11.7 & 12.50 \\
\hline Epoxy resin & 0.0333 & 0.0312 & 0.0324 & 0.0323 & 0.241 & 0.233 & 0.223 & 0.232 & 1.31 & 1.25 & 1.15 & 1.24 \\
\hline Nail polish & 0.589 & 0.589 & 0.587 & 0.588 & 5.01 & 5.03 & 5.07 & 5.037 & 18.4 & 18.5 & 18.5 & 18.47 \\
\hline Methyl alcohol & 0.343 & 0.342 & 333 & 4.693 & 8 & 7.97 & 7.97 & 0.142 & 30.9 & 30.5 & 31.2 & 0.77 \\
\hline Ethanol & 0.337 & 0.342 & 0.346 & 0.342 & 7.8 & 7.72 & 7.76 & 7.760 & 30.3 & 30 & 30.3 & 30.20 \\
\hline Isopropanol & 0.247 & 0.247 & 0.2447 & 0.246 & 7.77 & 7.77 & 7.74 & 7.760 & 30.6 & 30.4 & 30.4 & 30.47 \\
\hline DMSO & 0.356 & 0.352 & 0.342 & 0.350 & 4.18 & 4.27 & 4.42 & 4.290 & 14 & 14 & 14.4 & 14.13 \\
\hline Toluene & 0.329 & 0.294 & 0.294 & 0.306 & 6.64 & 6.64 & 7.11 & 6.797 & 25.3 & 25.6 & 27.1 & 26.00 \\
\hline Chloroform & 4.01 & 4.01 & 4.01 & 4.010 & 0.493 & 0.537 & 0.565 & 0.532 & 2.12 & 2.24 & 2.47 & 2.28 \\
\hline THF & 0.479 & 0.479 & 0.478 & 0.479 & 2.87 & 2.88 & 2.89 & 2.880 & 10.1 & 10.1 & 10.1 & 10.10 \\
\hline Acetone & 4.68 & 4.68 & 4.72 & 4.693 & 0.152 & 0.142 & 0.132 & 0.142 & 0.817 & 0.752 & 0.751 & 0.77 \\
\hline
\end{tabular}


surface with DMSO, but the results are not satisfactory. The use of THF had a slightly better effect, but still not enough. Additive treatments with only lacquer, lacquer primer and lacquer as well as nail polish did not result in a visual setting either. As in the case of PLA, they showed the layers on the side of the printout. Painting with nail polish - apart from the fact that it did not cover the visible layers - additionally left an irregular pattern on the surface. A positive result of additive treatment was obtained in the case of covering the surface of the printout with a finishing putty. The resulting layer was easy to process. Scratches visible on the drawing are imperceptible when moving the finger over the surface. The best results were obtained during the treatment with abrasive papers as well as after painting the previously ground surface. Grinding was much easier than grinding of PLA, because the material was easier to grind and did not plasticize. The use of epoxy resin covered all irregularities and significantly smoothed out the roughness. The most uniform result was obtained after immersion of the sample in acetone vapor. The surface is noticeably smooth, without any unevenness. The base color of the sample also remained. Chloroform vapors also improved surface quality, smoothing most of the roughness. The drawings do not show much because the surface was so smooth that the camera did not find a point where it could catch the focus. An additional problem was the white color of the material. The structure shown in the picture is smooth to the touch, as in the case of the PLA lacquer coating. Color changes are caused by the same factors as in the case of PLA. During abrasive treatment, a satisfactory surface quality was obtained after the use of the abrasive paper with the grain-size 500 for dry processing, while for wet processing a satisfactory result was achieved after the use of 320 paper. In addition, water facilitated dust extraction after treatment with the previous paper, which also improved the surface quality. The disadvantage of sanding paper was the uneven removal of the material. After grinding, it was noticed that the corners of the cube are more ground than the center of the cube walls.

\section{Measuring the surface quality of processed samples}

The roughness of each sample was measured with the TAYLOR HOBSON SURTRONIC 25 profile meter. $R a$ (arithmetic mean deviation from the mean line) and $R z$ (highest roughness height according to the 10 highest profiles measured) and $S m$ (mean roughness distance) were measured. The results are presented in Tables 4 and 5. For each of the samples three measurements were made and the arithmetic mean was calculated from them.

\section{CONCLUSIONS}

Comparing the results of organoleptic evaluation and roughness measurements with a profile gauge one can notice that the results are similar. The best results of sur- face smoothness were obtained during the treatment with abrasive papers and after the application of epoxy resin. Grinding produces large amounts of dust. A satisfactory effect was also obtained after treatment of PLA samples in chloroform vapor and ABS samples in acetone vapor. When starting the tests in a specific range, it is necessary to adjust the test methods in order to shorten the duration of the tests. It is important to introduce elimination tests to reduce the number of samples needed for preparation. It is equally important to eliminate as many factors influencing the final result as possible. It is preferable if there is one independent factor for the result, which can be clearly defined. When smoothing 3D prints in FFF technology, the material properties like hardness, softening temperature and chemical reactivity must be taken into account. This is important in order to select a suitable processing method. The machining methods that can be used in foundry engineering are grinding, epoxy resin coating and finishing putty. However, they have a disadvantage in the form of a change in shape and dimension. The treatment that provides the best results with a relatively small amount of work is the bathing of prints in the vapor of solvents. For PLA it will be chloroform, while for ABS it will be acetone. The only limitation is the ability to create a large enough chamber to fit the whole mode. Treatments with lacquer covering in order to change the color of the workpiece or to create a protective coating, require prior smoothing treatment and degreasing of the surface. In case of painting directly on an unsmoothed surface, the glossy paint will visually highlight the line of the layer. Weak solvents, i.e. ethyl alcohol, methyl alcohol, isopropanol do not react and do not dissolve the surface of prints. PLA reacts with THF and toluene, but the results are not satisfactory. The same state is achieved with ABS in contact with DMSO, chloroform and THF.

This research did not receive any specific grant from funding agencies in the public, commercial, or not-for-profit sectors.

\section{REFERENCES}

[1] Brenken B., Barocio E., Favaloro A. et al.: Additive Manufacturing 2018, 21, 1.

https://doi.org/10.1016/j.addma.2018.01.002

[2] Abbott A.C., Tandon G.P., Bradford R.L. et al.: Additive Manufacturing 2018, 19, 29.

https://doi.org/10.1016/j.addma.2017.11.002

[3] Heller B.P., Smith D.E., Jack D.A.: Additive Manufacturing 2016, 12 Part B, 252. https://doi.org/10.1016/j.addma.2016.06.005

[4] Goyanes A., Buanz A.B.M., Basit A.W., Gaisford S.: International Journal of Pharmaceutics 2014, 476, 88. http://dx.doi.org/10.1016/j.jpharm.2014.09.044

[5] Rytlewski P., Stepczyńska M., Moraczewski K. et al.: Polimery 2018, 63, 603. http://dx.doi.org/10.14314/polimery.2018.9.4 
[6] Moraczewski K., Malinowski R., Rytlewski P., Zenkiewicz M.: Polimery 2015, 60, 492. http://dx.doi.org/10.14314/polimery.2015.492

[7] Tanikella N.G., Wittbrodt B., Pearce J.M.: Additive Manufacturing 2017, 15, 40. https://doi.org/10.1016/j.addma.2017.03.005

[8] Zenkiewicz M., Richter J., Rytlewski P., Richter A.: Polimery 2011, 56, 489. http://dx.doi.org/10.14314/polimery.2011.489

[9] Mrówka M., Machoczek T., Jureczko P. et al.: Polish Journal of Chemical Technology 2019, 21, 1. http://dx.doi.org/10.2478/pjct-2019-0001

[10] Lunt J.: Polymer Degradation and Stability 1998, 59, 145. https://doi.org/10.1016/S0141-3910(97)00148-1

[11] Oksman K., Skrifivars M., Selin J.-F.: Composites Science and Technology 2003, 63, 1317. https://doi.org/10.1016/S0266-3538(03)00103-9

[12] Athanasiou K.A., Niederauer G.G., Agrawal C.M.: Biomaterials 1996, 17, 93. https://doi.org/10.1016/0142-9612(96)85754-1
[13] Drumright R.E., Gruber P.R., Henton D.E.: Advanced Materials 2000, 12, 1841. http://dx.doi.org/10.1201/9780203508206.ch16

[14] Olivera S., Muralidhara H.B., Venkatesh K. et al.: Journal of Materials Science 2016, 51, 3657. https://doi.org/10.1007/s10853-015-9668-7

[15] Harris B.D., Nilsson S., Poole Ch.M.: Australasian Physical \& Engineering Sciences in Medicine 2015, 38, 399. http://dx.doi.org/10.1007/s13246-015-0356-3

[16] Ozcelik B., Ozbay A., Demirbas E.: International Communications in Heat and Mass Transfer 2010, 37, 1359.

https://doi.org/10.1016/j.icheatmasstransfer.2010.07.001

[17] Ahn S.-H., Montero M., Odell D. et al.: Rapid Prototyping Journal 2002, 8, 248. https://doi.org/10.1108/13552540210441166

Received 30 IV 2019 